\title{
Correction to: A genome-wide association study identifies single nucleotide polymorphisms associated with time-to-metastasis in colorectal cancer
}

Michelle E. Penney ${ }^{1}$, Patrick S. Parfrey ${ }^{2}$, Sevtap Savas ${ }^{1,3}$ and Yildiz E. Yilmaz ${ }^{1,2,4^{*}}$ (i)

\section{Correction to: Penney et al. BMC Cancer (2019) 19:133} https://doi.org/10.1186/s12885-019-5346-5

Following publication of the original article [1], the authors reported that Fig. 3 was mistakenly replaced by Fig. 4. The correct Fig. 3 is given below:

\begin{abstract}
Author details
'Discipline of Genetics, Faculty of Medicine, Memorial University of Newfoundland, St. John's, Canada. ${ }^{2}$ Discipline of Medicine, Faculty of Medicine, Memorial University of Newfoundland, St. John's, Canada. ${ }^{3}$ Discipline of Oncology, Faculty of Medicine, Memorial University of Newfoundland, St. John's, Canada. ${ }^{4}$ Department of Mathematics and Statistics, Faculty of Science, Memorial University of Newfoundland, St. John's, Canada.
\end{abstract}

Received: 3 May 2019 Accepted: 3 May 2019

Published online: 10 May 2019

\section{Reference}

1. A genome-wide association study identifies single nucleotide

polymorphisms associated with time-to-metastasis in colorectal cancer. Penney et al BMC Cancer. 2019;19:133 https://doi.org/10.1186/s12885-019-

5346-5.

\footnotetext{
* Correspondence: yyilmaz@mun.ca

'Discipline of Genetics, Faculty of Medicine, Memorial University of Newfoundland, St. John's, Canada

${ }^{2}$ Discipline of Medicine, Faculty of Medicine, Memorial University of

Newfoundland, St. John's, Canada

Full list of author information is available at the end of the article
}

(c) The Author(s). 2019 Open Access This article is distributed under the terms of the Creative Commons Attribution 4.0 International License (http://creativecommons.org/licenses/by/4.0/), which permits unrestricted use, distribution, and reproduction in any medium, provided you give appropriate credit to the original author(s) and the source, provide a link to the Creative Commons license, and indicate if changes were made. The Creative Commons Public Domain Dedication waiver (http://creativecommons.org/publicdomain/zero/1.0/) applies to the data made available in this article, unless otherwise stated. 
(a)

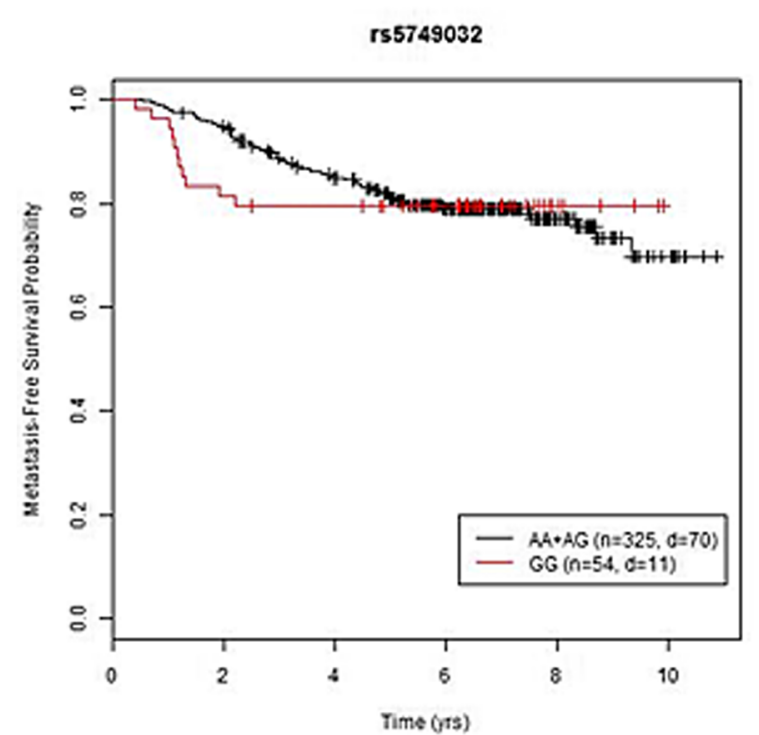

(b)

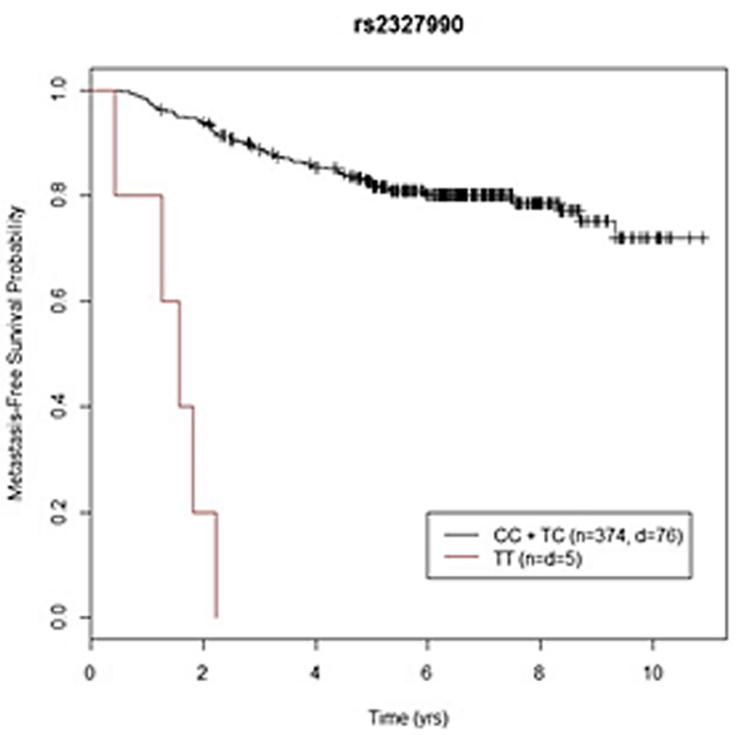

Fig. 3 Kaplan-Meier survival function for the most significant SNPs in the multivariable analysis under the (a) mixture cure model and (b) Cox proportional hazards regression model. n: number of patients in that genotype category; d: number of metastasis in that genotype category. a rs5749032 was the only SNP maintaining genome-wide significance after the multivariable analysis using the mixture cure model. In the rs5749032 GG genotype subgroup, the clear plateau at approximately $80 \%$ metastasis-free survival probability indicates the existence of a large proportion of long-term metastasis-free survivors. $\mathbf{b}$ In the rs2327990 TT genotype subgroup, all the patients experienced metastasis within approximately the first two years. Therefore, a standard survival analysis method is appropriate 